doi:10.1016/j.corsci.2006.10.027

0010-938X/\$ - see front matter (C 2006 Elsevier Ltd. All rights reserved.

As published in Corrosion Science 49 (2007) 2371-2391

www.elsevier.com/locate/corsci

http://www.elsevier.com/wps/find/journaldescription.cws_home/260/description?navopenmenu=-2

\title{
Mechanisms of corrosion inhibition of AA2024-T3 by vanadates
}

\author{
M. Iannuzzi ${ }^{*}$, G.S. Frankel \\ Fontana Corrosion Center, The Ohio State University Columbus, OH 43210, United States
}

Received 27 September 2006; accepted 16 October 2006

Available online 16 January 2007

\begin{abstract}
The mechanisms of corrosion inhibition of AA2024-T3 by vanadates were studied using chronoamperometry, polarization curves and adsorption isotherms. The electrochemical behaviour of clear solutions containing metavanadates and orange solutions containing decavanadates was clearly distinctive. Metavanadates reduced the kinetics of oxygen reduction to an extent similar to chromates. Corrosion inhibition of AA2024-T3 by metavanadates was very rapid and it might occur by the formation of an adsorbed layer. Reduction of clear metavanadate solution was very slow. Approximately 35 min were required to develop a monolayer of a reduced vanadate species. The adsorption of the inhibitor likely blocked reactive sites on intermetallic particles, discouraging the oxygen reduction reaction (ORR). Adsorption of the inhibitor on the $\mathrm{Al}$ matrix could also displace $\mathrm{Cl}^{-}$ions, increasing the stability of the passive film and reducing the breakdown of S-phase particles. In contrast, decavanadates were shown to be poor inhibitors of the ORR. A sharp current spike was observed after injection of decavanadates for both $\mathrm{Cu}$ and AA2024-T3 at various applied cathodic potentials. Integration of the current peaks suggested the formation of several monolayers of a reduced vanadate species. The formation of several monolayers was in line with the poor performance of decavanadates as inhibitors of AA2024-T3 corrosion.
\end{abstract}

* Corresponding author. Tel.: +1 614761 6959. E-mail address:

mariano.iannuzzi@dnv.com (M. Iannuzzi). 


\section{Introduction}

Aluminium alloy 2024-T3 (AA2024-T3) is a heat-treatable high strength aluminium alloy that is used as fuselage skin and structural material in aircraft design due to the combination of good mechanical properties and light weight $[1,2]$. However, AA2024-T3 is susceptible to localized corrosion. The susceptibility of aluminium alloys to localized corrosion strongly depends on the distribution and electrochemical properties of intermetallic compounds (IMCs) and second phase particles [3-9]. Aluminium alloys for aerospace applications are protected from the aggressive environment using multi-layered coating systems based on the chemistry of chromates [10-17]. A suitable candidate for chromate replacement has not yet been developed for the most demanding applications [10].

In a recent publication, we discussed the complex speciation of the vanadate system in aqueous solutions of interest for corrosion studies [18]. In short, as-prepared solutions of $\mathrm{NaVO}_{3}$ dissolved in $0.5 \mathrm{M} \mathrm{NaCl}$ remain colourless. According to ${ }^{51} \mathrm{~V}$ nuclear magnetic resonance spectroscopy (NMR), clear metavanadate solutions contain monovanadate $\left(\mathrm{V}_{1}\right)$, divanadate $\left(\mathrm{V}_{2}\right)$, tetravanadate $\left(\mathrm{V}_{4}\right)$ and pentavanadate $\left(\mathrm{V}_{5}\right)$ species [19-23]. Polymerization of these oligomers to form orange decavanadates $\left(\mathrm{V}_{10}\right)$ occurs during acidification [19,20,22-25]. Thus, if the $\mathrm{pH}$ of clear solutions is adjusted to $\mathrm{pH} 4$, only signal from $\mathrm{V}_{10}$ is detected by ${ }^{51} \mathrm{~V}$ $\mathrm{NMR}$, indicating complete polymerization of $\mathrm{V}_{1}-\mathrm{V}_{5}$. Re-adjusting the $\mathrm{pH}$ of the orange electrolytes to $\mathrm{pH} 8.71$ partially de-polymerizes $\mathrm{V}_{10}$ to give $\mathrm{V}_{2}, \mathrm{~V}_{4}$, and $\mathrm{V}_{5} \cdot{ }^{51} \mathrm{~V}$ NMR also showed that the monovanadates are present exclusively in clear metavana date electrolytes. In contrast, $\mathrm{V}_{10}$ and $\mathrm{V}_{4}$ are the predominant species in orange solutions [18].

The electrochemical behaviour of A2024-T3 in clear metavanadate solutions containing monovanadates but no decavanadates was markedly different than in orange solutions containing decavanadates but no monovanadates [18]. The presence of monovanadates remarkably reduced the rate of the oxygen reduction reaction (ORR) to an extent comparable to values reported for chromates [18]. On the contrary, orange solutions containing decavanadates did not lower the rate the ORR significantly.

The corrosion inhibition mechanisms of clear metavanadate and orange decavanadate solutions have been investigated [26,27]. The injection of clear metavanadate solutions containing monovanadate $\left(\mathrm{V}_{1}\right)$ to the cathode side of different split cell setups reduced the galvanic current to a large extent, confirming a potent inhibition of the ORR. The reduction in galvanic current was not accompanied by a current spike that might be attributed to vanadate reduction. In all cases a rapid decay in galvanic current was observed. These findings are in clear contrast to results obtained by Clark et al. for the chromate system [28,29]. Injection of $\mathrm{Cr}^{6+}$ during split cell experiments and chronoamperometry produced a sharp current spike. These transient events were associated with the formation of a $\mathrm{Cr}^{3+}$ monolayer by reduction of $\mathrm{Cr}^{6+}$, which inhibited the ORR and further $\mathrm{Cr}^{6+}$ reduction. The absence of a reduction peak after injection of metavanadates suggested that metavanadates lowered the rate of the ORR by adsorbing on the surface and blocking sites rather than by a reduction process.

In contrast, the injection of orange solutions containing decavanadates but no monovanadates generated a current peak possibly associated with $\mathrm{V}_{10}$ reduction, followed by a modest decrease in current [18]. This suggests that the reduction of decavanadates did not form a protective film as in the case of chromates. The fact that a difference in speciation gave such a contrast in electrochemical behaviour is a very interesting phenomenon that requires further investigation. 
In this paper, chronoamperometry, polarization curves and adsorption isotherms were utilized to further analyze the mechanisms of inhibition by vanadates. In addition the formation of a vanadium rich surface film was studied by X-ray photoelectron spectroscopy (XPS). The residual protection of the film was also investigated.

Adsorption isotherms are commonly used in corrosion inhibition studies [30,31]. Adsorption isotherms describe the equilibria of the adsorbed species at the electrode/electrolyte interface [31]. All adsorption isotherms can be described by a generalized equation [31]:

$$
f(\theta, x) \exp (-a \theta)=K C_{\mathrm{i}}
$$

where $\theta$ represents the adsorption coverage, $\mathrm{x}$ the molecular interaction parameter, $\mathrm{x}$ the size ratio, $\mathrm{K}$ the adsorption constant and $\mathrm{C}_{\mathrm{i}}$ the concentration of the inhibitor [31]. The function $\mathrm{f}(\theta, \mathrm{x})$ is the configurational term, which depends on the assumptions made to derive the isotherms [31]. As explained by Kern and Landolt, the size ratio $\mathrm{x}$ represents the relative size of the adsorbate compared to the solvent molecules [4]. The molecular interaction parameter $\mathrm{x}$ accounts for the lateral interactions between adsorbed species [31]. In general, adsorption isotherms contain either $\mathrm{x}$ or a, but rarely both parameters [31]. Analysis of the two parameter isotherms is done by linear fitting of the double logarithmic curves [30,31]. The Lang muir isotherm represents the simplest case where each active surface site can accommodate only one adsorbate molecule with no lateral interaction between them [32]:

$$
\frac{\theta}{(1-\theta)}=K C_{\mathrm{i}} \quad \text { or } \quad \frac{C_{\mathrm{i}}}{\theta}=\frac{1}{K}+C_{\mathrm{i}}
$$

where $\theta$ is the surface coverage, $\mathrm{K}$ the adsorption equilibrium constant and $\mathrm{C}_{\mathrm{i}}$ the concentration of the inhibitor. Assuming that complete coverage of the surface gives $100 \%$ reduction in current, it is common to define $\theta$ as:

$$
\theta=1-\frac{i_{\text {(inhibitor) }}}{i_{\text {(free) }}}
$$

where $i_{\text {(inhibitor) }}$ represents the corrosion rate in the presence of an inhibitor and $i_{\text {(free) }}$ the rate in the absence of an inhibitor [30]. This definition is general and $i_{\text {(free) }}$ and $i_{\text {(inhibitor) }}$ can be readily replaced by polarization resistance, or weight lost values $[30,31,33]$. When evaluating a cathodic inhibitor it is common to use the current measured at an arbitrary cathodic potential. In general, $\theta$ represents the corrosion inhibition efficiency. The adsorption equilibrium constant $\mathrm{K}$ is related to the free energy of adsorption by [33-35]:

$$
K=\frac{1}{55.5} \exp \left(\frac{-\Delta G_{\mathrm{abs}}^{0}}{R T}\right)
$$

where $\mathrm{K}$ is the adsorption equilibrium constant in $(1 / \mathrm{mol}), \Delta G_{\text {abs }}^{0}$ is the free energy of adsorption in $(\mathrm{J} / \mathrm{mol}) ; \mathrm{R}$ represents the gas constant $(8.31$ $\mathrm{J} / \mathrm{mol} \mathrm{K}$ ) and T the temperature in Kelvin.

\section{Experimental}

\subsection{Materials and sample preparation}

Sodium vanadium oxide, $98 \% \mathrm{NaVO}_{3}$, and reagent-grade sodium chloride were obtained from Sigma-Aldrich. All solutions were prepared with 18.2 M $\Omega$-cm deionised water. Clear metavanadate solutions containing monovanadate and orange solutions containing 
decavanadates were prepared as described previously [18]. In short, metavanadate solutions were prepared by dissolving $\mathrm{NaVO} 3$ in $0.5 \mathrm{M} \mathrm{NaCl}$ and adjusting the as-prepared $\mathrm{pH}$ to the higher value of 8.71. Orange solutions containing decavanadates were prepared by acid ification of the clear solutions to $\mathrm{pH} 4$ using concentrated $\mathrm{HCl}$, and subsequent re-adjustment to $\mathrm{pH}$ 8.71. Prepared in this fashion, monovanadates (V1) are present only in clear solutions and decavanadates $\left(\mathrm{V}_{10}\right)$ are present only in orange electrolytes [18]. For simplicity, these solutions will be referred to as orange decavanadate and clear metavanadate solutions, respectively, even though the former solutions also contain some metavanadates. Two different AA2024-T3 panels (nominal composition 3.8-4.9\% Cu, 1.2-1.8\% Mg, 0.3-0.9\% Mn, 0.5\% Fe, $0.5 \% \mathrm{Si}, 0.25 \% \mathrm{Zn}, 0.1 \% \mathrm{Cr}, 0.05 \% \mathrm{Ti}$, balance $\mathrm{Al}$ ), were tested with 1 and $5 \mathrm{~mm}$ thickness, respectively. The samples were mounted in epoxy resin, exposing the rolled surface; ground through 1200 grit $\mathrm{SiC}$ papers (Buehler), and polished with 3 and $1 \mu \mathrm{m}$ diamond paste (Buehler). Ethyl alcohol $(<0.2 \%$ water) was used as lubricant during all the surface preparation stages to minimize corrosion damage during grinding and polishing. Pure $\mathrm{Cu}$ (99.95\%) coupons were cut from $50 \mathrm{~mm}$ plates, mounted in epoxy resin and polished following similar procedures.

\subsection{Chronoamperometry}

Effects of metavanadate and decavanadate injections at varied applied potentials were investigated by measuring the time evolution of the cathodic current at constant applied potential. Concentrated solutions containing metavanadates or decavanadates were injected to make $5 \mathrm{mM}$ total vanadate after mixing. The final $\mathrm{pH}$ after mixing was 7.6 in all the experiments. A VoltaLab PGP-201 potentiostat was used with a platinum mesh counterelectrode and a SCE reference electrode.

\subsection{Potentiodynamic polarization curves}

Electrochemical tests were carried out using either a Gamry PC3/300 or a VoltaLab PGP201 potentiostat. In both chronoamperometry and electrochemical tests, a Luggin capillary filled with an agar-agar gel made with $0.5 \mathrm{M} \mathrm{NaCl}$ was used. Samples were cleaned and degreased with ethyl alcohol before testing. Each experiment was repeated at least in triplicate.

Cathodic polarization experiments were carried out in aerated and deaerated solutions. Aeration was achieved by bubbling purified compressed air for $1 \mathrm{~h}$ prior to the experiment. The air flow was reduced but not stopped during measurements. The solution was stirred during the experiment to generate a more reproducible limiting current for the ORR $\left(i_{\mathrm{L}}\right)$. Deaeration was achieved by $1 \mathrm{~h}$ Ar degassing and stirring. After $1 \mathrm{~h}$, samples were lowered into the electrolyte and the OCP was measured for $15 \mathrm{~min}$. The flow of Ar was reduced but not stopped during the experiment. The potential sweep started $10 \mathrm{mV}$ above OCP and was stopped when the current density reached $-2 \mathrm{~mA} / \mathrm{cm}^{2}$. A scan rate of $1 \mathrm{mV} / \mathrm{s}$ was used and the total exposed area was approximately $1 \mathrm{~cm}^{2}$.

\subsection{X-ray photoelectron spectroscopy}

Vanadium at the surface was investigated by XPS. $\mathrm{Cu}$ and AA2024-T3 samples were polarized at fixed cathodic potentials for $3 \mathrm{~h}$. Concentrated $150 \mathrm{mM}$ metavanadate and 
decavanadate solutions were injected after 15 min to make $5 \mathrm{mM}$ total vanadate after dilution. Samples were removed under potential control and gently rinsed with DI water. The coupons were allowed to dry in a desiccator under low vacuum. XPS spectra were acquired using a Kratos Axis Ultra with a monochromated Al X-ray source at $130 \mathrm{~W}$.

\section{Results}

\subsection{Chronoamperometry}

To investigate the mechanisms of corrosion inhibition by vanadates, experiments at different fixed potentials were performed on $\mathrm{Cu}$ and AA2024-T3. Similarly, the evolution of the current and the effects of injecting either clear metavanadate or orange decavanadate solutions, to make $5 \mathrm{mM}$ total vanadate after mixing, were investigated. Fig. 1a shows the effects of clear metavanadate injections for a $\mathrm{Cu}$ sample polarized at three different potentials. Injection of solution containing monovanadates produced a rapid reduction in cathodic current, with no current peak. A summary of the percentage of reduction in
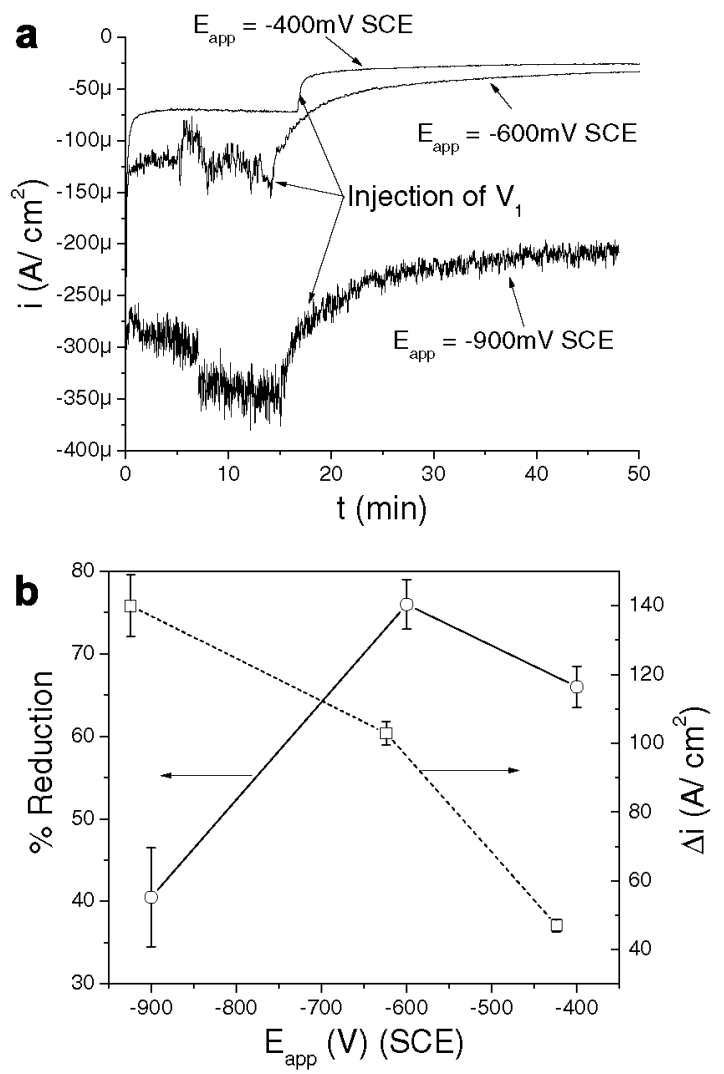

Fig. 1. Chronoamperometry of $\mathrm{Cu}$ in aerated $0.5 \mathrm{M} \mathrm{NaCl}$. (a) Effects of clear metavanadate injections on the cathodic current at different applied potentials $\left(E_{\text {app }}\right)$. (b) Summary of the percentage of reduction in current and actual current density difference after clear metavanadate injection. 
current and the actual difference in current density $(\Delta i)$ before and after injection of the clear metavanadate solutions is shown in Fig. 1b. The percentage of current reduction, which can also be thought of as the inhibition efficiency, reached a maximum value of $76 \%$ at an applied potential of $-600 \mathrm{mV} \mathrm{SCE}$. The total current density difference increased as the applied potential decreased. Experiments were also performed on AA2024-T3 and pure Al. No current peaks were observed even at very negative applied potentials.

Since the maximum amount of inhibition by clear metavanadate solutions occurred at an applied potential of $-600 \mathrm{mV} \mathrm{SCE}$, it was of interest to compare the effects of injecting orange decavanadate solutions at the same applied potential. Results of injecting orange decavanadate solutions on $\mathrm{Cu}$ at $-600 \mathrm{mV} \mathrm{SCE}$ are shown in Fig. 2. Injection of the solution containing decavanadates was followed by a sharp increase in current that reached approximately -400 $\mu \mathrm{A} / \mathrm{cm}^{2}$. The duration of the current transient was approximately $12 \mathrm{~min}$. After $60 \mathrm{~min}$, the current was lower than before injection, but only by $27 \%$. Reproducibility of these experiments was good, and the average reduction in cathodic current was $30 \pm 5 \%$. The duration of the current transient varied from 7-12 min, and the maxi mum current density reached after injecting the orange decavanadate solution was in all cases approximately $-400 \mu \mathrm{A} / \mathrm{cm}^{2}$. The charge associated with the current peaks was $3.23 \pm 0.5 \mathrm{mC} / \mathrm{cm}^{2}$.

Experiments on AA2024-T3 samples at a fixed potential of $-900 \mathrm{mV} \mathrm{SCE}$ were per formed to investigate whether the current transients occurred exclusively on $\mathrm{Cu}$ surfaces. The potential of $-900 \mathrm{mV}$ SCE was chosen since it was the potential measured on AA2024/AA2024 split cell experiments before injection [27]. Fig. 3 shows the result of injecting orange decavanadate solution to AA2024-T3 at $-900 \mathrm{mV}$ SCE. At $20 \mathrm{~min}$, the injection of the orange solution containing decavanadates produced a current peak that lasted approximately 7-8 min, and reached a maximum cathodic current of $-50 \mu \mathrm{A} / \mathrm{cm}$. After $60 \mathrm{~min}$, a small reduction in cathodic current of about $33 \%$ relative to the cur rent before injection was observed.

Experiments also were performed in deaerated electrolytes to analyze the effects of oxygen on the inhibition mechanisms and performance. Because the injected solutions containing the inhibitors were not deaerated, the results of injecting aerated $0.5 \mathrm{M} \mathrm{NaCl}$

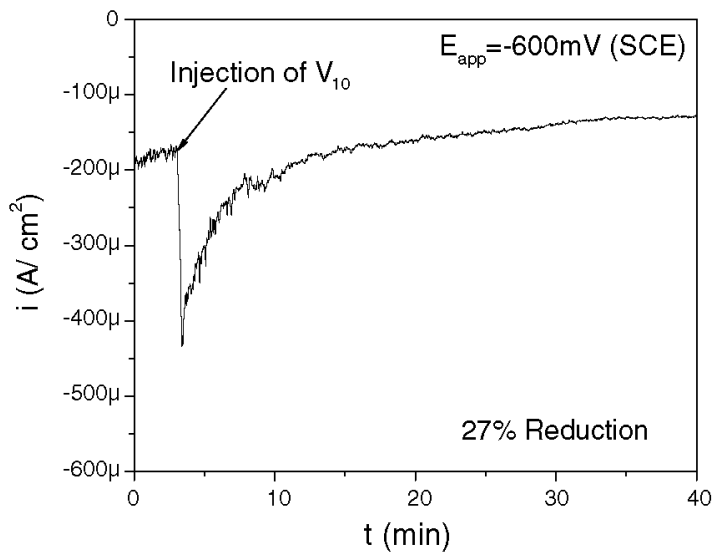

Fig. 2. Chronoamperometry of $\mathrm{Cu}$ in aerated $0.5 \mathrm{M} \mathrm{NaCl}$. Effects of injection of orange decavanadate solution on the cathodic current at $E_{\text {app }}=-600 \mathrm{mV}(\mathrm{SCE})$. 


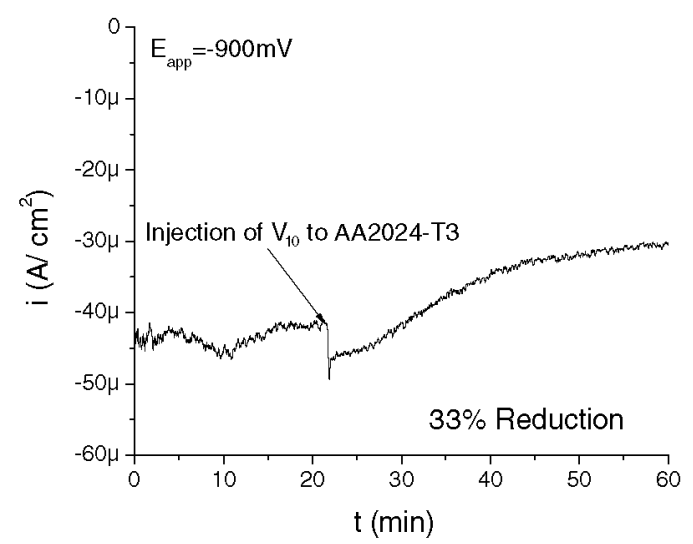

Fig. 3. Chronoamperometry of AA2024-T3 in aerated $0.5 \mathrm{M} \mathrm{NaCl}$. Effects of injection of orange decavanadate solutions on the cathodic current at $E_{a p p}=-900 \mathrm{mV} \mathrm{SCE}$.

without vanadate were also analyzed. Fig. 4 summarizes the effects of injecting $0.5 \mathrm{M} \mathrm{NaCl}$ with no inhibitor or $0.5 \mathrm{M} \mathrm{NaCl}$ containing clear metavanadate solution into the deaerated 0.5 $\mathrm{M} \mathrm{NaCl}$ electrolyte at an applied potential of $-600 \mathrm{mV}$ SCE for a $\mathrm{Cu}$ electrode. Injection of the aerated $0.5 \mathrm{M} \mathrm{NaCl}$ solution into the deaerated electrolyte produced a small increase in cathodic current. The current returned to the steady state values within minutes due to the constant purging of the system with Ar. Injection of clear metavanadate solution at $15 \mathrm{~min}$ produced a current peak that reached $-17 \mu \mathrm{A} / \mathrm{cm}^{2}$. After the initial transient, the current did not recover the initial value and remained at $-2 \mu \mathrm{A} / \mathrm{cm}^{2}$. It is interesting to note that in aerated conditions injection of clear metavanadate solution rapidly reduced the cathodic current without a current peak. The difference in behaviour will be discussed below. Under similar conditions, injection of orange decavanadate solution into the deaerated electrolyte produced a larger increase in cathodic

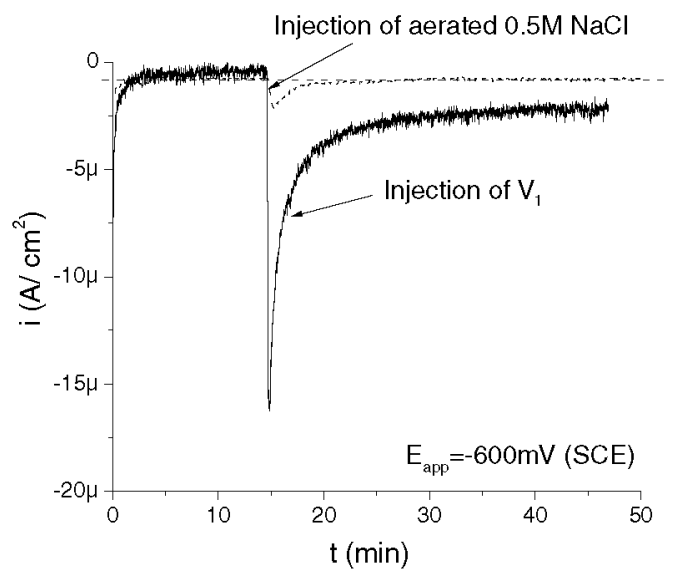

Fig. 4. Chronoamperometry of $\mathrm{Cu}$ in deaerated $0.5 \mathrm{M} \mathrm{NaCl}$. Effects of injections of clear metavanadate solutions on the cathodic current at $E_{a p p}=-600 \mathrm{mV} \mathrm{SCE}$. Effects of aerated $0.5 \mathrm{M} \mathrm{NaCl}$ injection shown as reference. 


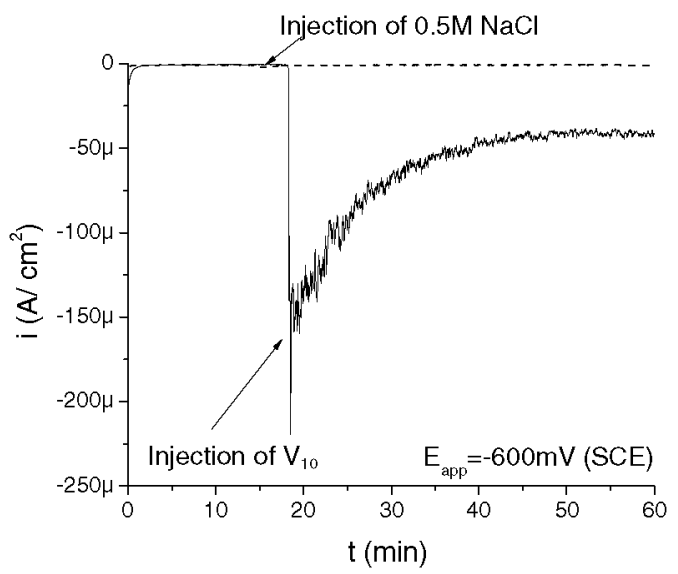

Fig. 5. Chronoamperometry of $\mathrm{Cu}$ in deaerated $0.5 \mathrm{M} \mathrm{NaCl}$. Effects of injections of orange decavanadate solutions on the cathodic current at $E_{a p p}=-600 \mathrm{mV} \mathrm{SCE}$. Effects of aerated $0.5 \mathrm{M} \mathrm{NaCl}$ injection shown as reference.

current that reached $-200 \mu \mathrm{A} / \mathrm{cm}^{2}$, Fig. 5. The current did not recover the initial level of -166 $\mathrm{nA} / \mathrm{cm}^{2}$, and stabilized at $-42 \mu \mathrm{A} / \mathrm{cm}^{2}$.

\subsection{X-ray photoelectron spectroscopy}

The objective of this analysis was to detect the presence of vanadium at the surface and, possibly, its oxidation state. Spectra for $\mathrm{C}, \mathrm{Cu}$ or $\mathrm{Al}, \mathrm{O}$ and $\mathrm{V}$ were recorded. The position of the $\mathrm{C} 1 \mathrm{~s}$ peak at $284.5 \mathrm{eV}$ was used to calibrate the spectra. Fig. 6 summarizes the oxygen $1 \mathrm{~s}$ and vanadium $2 p$ spectra for both $\mathrm{Cu}$ and AA2024 samples in different conditions.

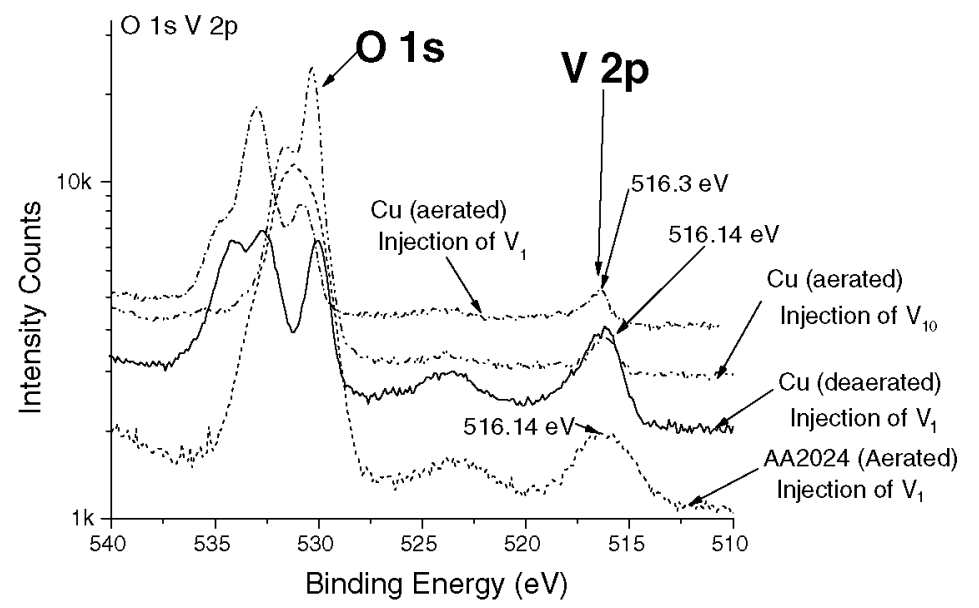

Fig. 6. Oxygen 1s Vanadium 2p spectra after $2 \mathrm{~h}$ exposure to solutions containing monovanadates or decavanadates at fixed potential under different aeration conditions as indicated. $\mathrm{Cu}$ sampled held at $-600 \mathrm{mV} \mathrm{SCE}$ and AA2024 samples held at $-900 \mathrm{mV}$ SCE. 
In comparison to the other elements, the intensity of the vanadium peaks was very small. The vanadium peaks were at a binding energy in the range of $516.14-516.3 \mathrm{eV}$ with an experimental error of $0.2 \mathrm{eV}$.

\subsection{Residual protection}

Since XPS analysis revealed the presence of a surface film rich in vanadium, it was of interest to investigate whether that film imparted some protection to $\mathrm{Cu}$. To form a vanadium film, $\mathrm{Cu}$ samples were exposed to solutions containing either monovanadates or decavanadates at a fixed potential of $-600 \mathrm{mV}$ SCE. After $2 \mathrm{~h}$, samples were removed under potential control, rinsed with DI water and dried in a desiccator for $24 \mathrm{~h}$. Thereafter, $\mathrm{Cu}$ samples were exposed to the base $0.5 \mathrm{M} \mathrm{NaCl}$ electrolyte with no inhibitor added in aerated conditions with stirring. Residual protection was assessed by measuring the time evolution of the current at the same fixed potential of $-600 \mathrm{mV}$ SCE. If the vanadium layer imparts some protection, a cathodic current smaller than the current measured for bare $\mathrm{Cu}$ in the same conditions would be expected. Fig. 7a shows the effects of the surface film formed on $\mathrm{Cu}$ by exposure to clear metavanadates. The current in the presence of the

Fig. 7. Chronoamperometry of $\mathrm{Cu}$ at $-600 \mathrm{mV} \mathrm{SCE}$ after to $2 \mathrm{~h}$ exposure to (a) clear metavanadate, and (b) orange
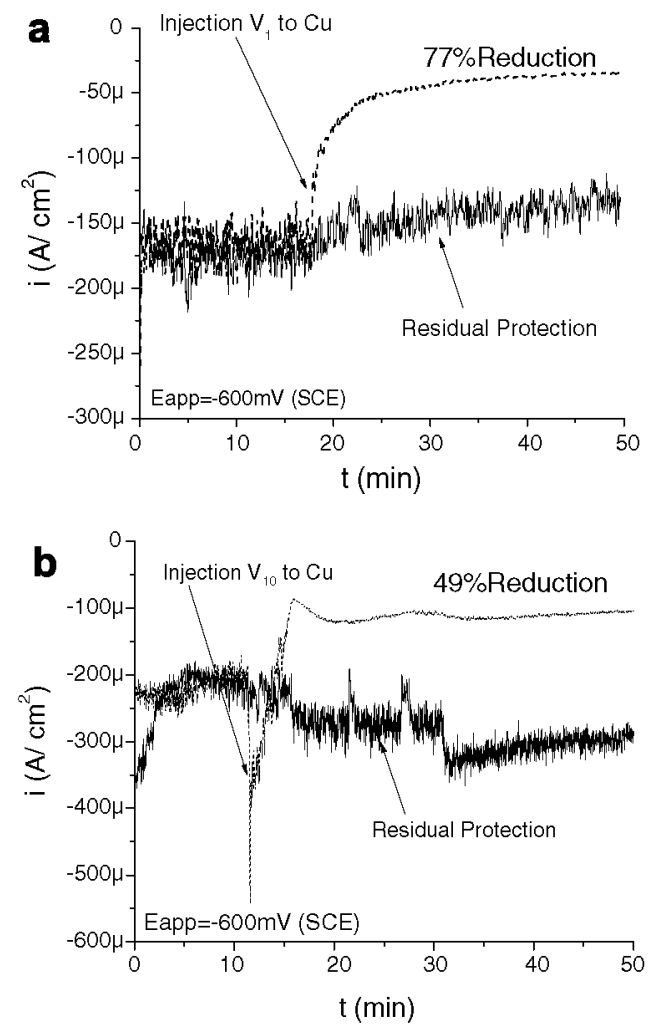

decavanadate (solid lines). In both figures dashed lines represent the effects of injecting the inhibitor in the as-polished $\mathrm{Cu}$ surface. 
$\mathrm{V}$ surface film was identical to the current on bare $\mathrm{Cu}$, and the effect of injecting a clear metavanadate solution is seen to be much greater. Similar results were found analyzing surface films formed by exposing $\mathrm{Cu}$ to orange decavanadates at the same potential, Fig. 7b. These findings suggest that the surface films were not robust and imparted no reduction of the ORR in a solution without inhibitor.

\section{Discussion}

\subsection{Chronoamperometry}

The reversible potential for the reduction of the different metavanadates depends on $\mathrm{pH}$ and total vanadate concentration [36]. The reversible potential at $\mathrm{pH} 7.6$ for the $\mathrm{HVO}_{4}{ }^{2-} / \mathrm{HV}_{2} \mathrm{O}_{3}{ }^{-}$ reduction reaction is approximately $-420 \mathrm{mV} \mathrm{SCE}$ and for the $\mathrm{H}_{2} \mathrm{VO}_{4} / \mathrm{HV}_{2} \mathrm{O}_{5}{ }^{-}$reduction reaction approximately $-380 \mathrm{mV} \mathrm{SCE}$. Likewise, the reversible potential for the reduction of divanadates, $\mathrm{H}_{3} \mathrm{~V}_{2} \mathrm{O}_{7}{ }^{-} / \mathrm{HV}_{2} \mathrm{O}_{5}{ }^{-}$, is approximately $-300 \mathrm{mV} \mathrm{SCE}$ [36]. V NMR data were used to obtain the concentration of the different vanadate species needed to calculate the reversible potentials [18]. Consequently, lower applied potentials should increase the driving force for those reactions to occur. However, in aerated conditions no current spike was observed upon injection of clear metavanadate solution. The absence of a current spike associated with the electrochemical reduction of the inhibitor suggests that the inhibition results from a surface film formed by adsorption.

To evaluate if there was a dependency of inhibition on concentration of metavanadates, adsorption isotherms were constructed using the cathodic polarization plots. Cathodic polarization curves were measured on AA2024-T3 samples in aerated conditions with stir ring. The concentration of clear metavanadates varied from $0.001-5 \mathrm{mM}$. The $i_{\text {(inhibitor) }}$ and the $\mathrm{i}\left(\mathrm{f}_{\text {ree }}\right)$ were determined by extrapolating the linear regions observed in cathodic polarization plots to the high potential of $-700 \mathrm{mV} \mathrm{SCE}$. This definition is arbitrary but gives a fair representation of the behaviour of the system.

Fig. 8 shows cathodic polarization curves, the inhibition efficiency and the actual cathodic current measured at $-700 \mathrm{mV} \mathrm{SCE}$ as a function of concentration of monovanadate (determined by V NMR [18]). The $\mathrm{pH}$ of the solutions was fixed at $\mathrm{pH}$ 7.6, which corresponds to the asprepared $\mathrm{pH}$ of a $5 \mathrm{mM}$ clear metavanadate solution. The Langmuir adsorption isotherm is shown in Fig. 9. The cathodic polarization curves showed that the cathodic current associated with the ORR was gradually reduced by incremental amounts of the inhibitor, Fig. $8 \mathrm{a}$ and $\mathrm{b}$. Therefore, the inhibition efficiency increased with incremental amounts of monovanadates, Fig. 8c. The minimum concentration of mono vanadate that reduced the cathodic kinetics of oxygen reduction was $0.005 \mathrm{mM}$. Inhibition jumped from $0 \%$ to $80 \%$ when the monovanadate concentration increased from $0.005 \mathrm{mM}$ to $0.007 \mathrm{mM}$. This critical concentration of inhibitor is extremely low and similar to the reported critical concentration of $\mathrm{Cr}^{6+}[10,15,18,37-39]$. Langmuir isotherms gave the best fit of the data, suggesting that there were no lateral interactions between adsorbed molecules. $C_{\mathrm{i}} / \theta$ scaled with both monovanadate and total metavanadate concentrations. How ever, the best fit of the data was obtained using the concentration of monovanadate. The slope was almost unity and $1 / \mathrm{K}$ was approximately 0.0017

$(1 / \mathrm{mol})$. Using the data obtained by fitting of the adsorption isotherm, a $\Delta \mathrm{G}^{0}$ abs of $-25.12 \mathrm{~kJ} / \mathrm{mol}$ is obtained. This value is in good agreement with data reported in the literature and the negative sign rep resents that adsorption is spontaneous $[31,33-35,40]$. This also suggests that adsorption 

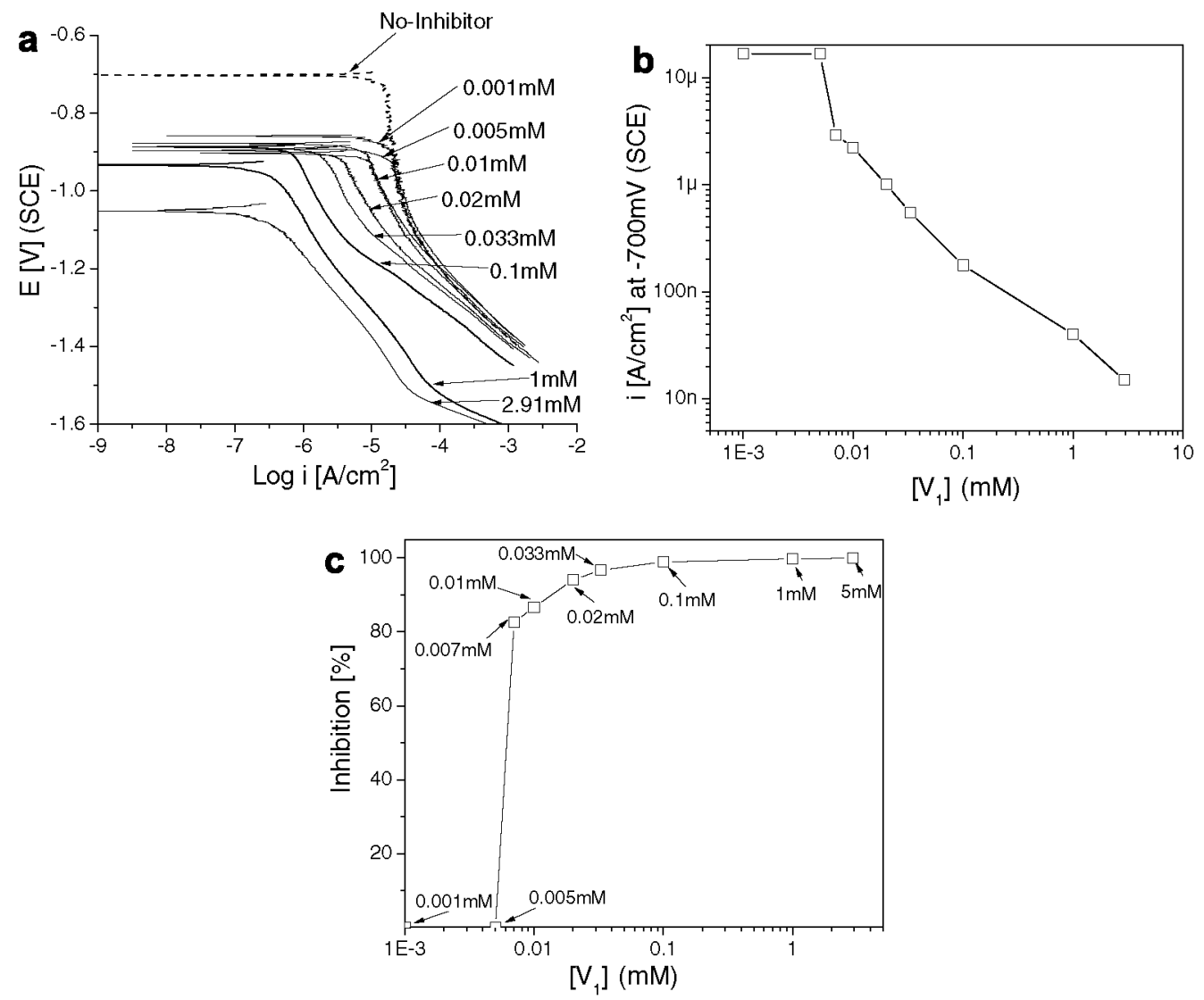

Fig. 8. (a) Cathodic polarization of AA2024-T3 in aerated conditions at varied monovanadate concentrations, $\mathrm{pH}$ 7.6, (b) current measured at the high potential of $-700 \mathrm{mV} \mathrm{SCE}$ vs V1 concentration, (c) inhibition as a function of V1 concentration.

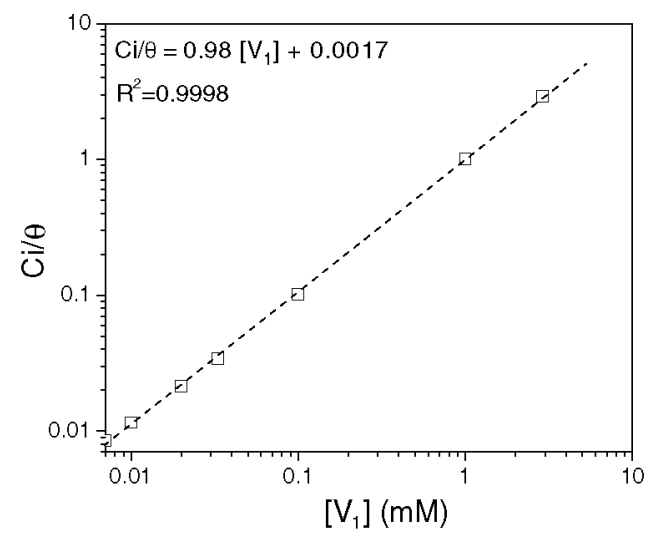

Fig. 9. Adsorption isotherm using the Langmuir equation. 
occurs immediately after injection of the clear metavanadate solution. $\Delta \mathrm{G}_{\text {abs }}^{0}$ ranging from -15 to $-30 \mathrm{~kJ} / \mathrm{mol}$ indicates that the molecules are physically adsorbed rather than chemisorbed. Chemisorption is characterized by free energies of about $-100 \mathrm{~kJ} / \mathrm{mol}[41]$.

Chronoamperometry in deaerated conditions was performed to de-convolute the influence of oxygen. The results are shown in Fig. 4. Injection of clear metavanadate solutions under deaerated conditions did produce a cathodic current peak. Previous studies by ${ }^{51} \mathrm{~V}$ NMR spectroscopy and polarization curves showed that, even though clear metavanadate solutions contain monovanadates, divanadates, tetravanadates and pentavanadates, monovanadates imparted the outstanding corrosion inhibition performance [18]. There fore, the current peak observed in deaerated conditions might represent the reduction of monovanadates. The reduction was not self-limiting and reached a steady state value of approximately $-2.4 \mu \mathrm{A} / \mathrm{cm}$. Results of integrating the current spectrum over the duration of the test are shown in Fig. 10. For this calculation, reduction from $\mathrm{V}^{5+}$ to $\mathrm{V}^{4+}$ was assumed (1 equivalent/mol). Monovanadate molecules are significantly smaller than decavanadates and their average size is $450 \mathrm{pm}$ [41]. Upon injection of chromates, a monolayer formed rapidly and the robust corrosion protection was assumed to be a consequence of the $\mathrm{Cr}$ monolayer [28]. In contrast, the formation of a monolayer of the reduced vanadium species took approximately $35 \mathrm{~min}$. Moreover, the reduction of clear metavanadate solution was not self-limited as it is with chromates. The current associated with the reduction of clear metavanadate solution is very small and lies within the current noise level of the experiments performed in aerated conditions, where no current peak was observed. Thus, it is possible that reduction of the adsorbed layer occurred even in the presence of oxygen. However, because inhibition occurred rapidly and the reduction of clear meta vanadate solution was a very slow process, the corrosion protection seems to be a consequence of the adsorption of the monovanadates, and not from the formation of reduced species.

Cathodic polarization curves can be used to gain a better understanding of this behaviour. Cathodic polarization curves for AA2024-T3 in solutions with and without meta vanadates in both aerated and deaerated conditions are shown in Fig. 11a. In aerated

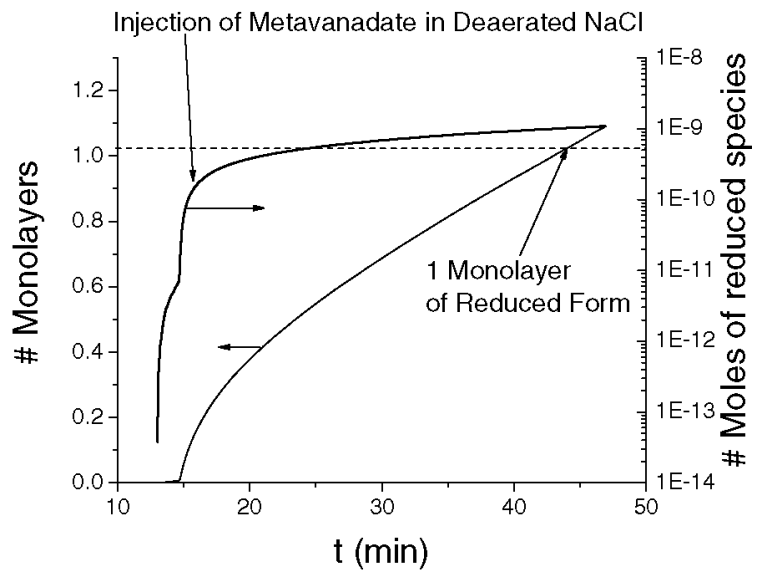

Fig. 10. Concentration of the reduced species and number of monolayers as a function of immersion time for $\mathrm{Cu}$ after injection of clear metavanadate solution in deaerated $0.5 \mathrm{M} \mathrm{NaCl}$. 
conditions in the absence of inhibitor, an open circuit potential (OCP) of about $-590 \mathrm{mV} \mathrm{SCE}$ was measured. The limiting current $\left(i_{\mathrm{L}}\right)$ in such conditions was about $-32 \mu \mathrm{A} / \mathrm{cm}^{2}$. Removing $\mathrm{O}_{2}$ by purging the system with Ar reduced the OCP to approximately $-1.05 \mathrm{~V}$ SCE. No limiting current was observed and the measured current mostly represents $\mathrm{H}_{2}$ gas evolution. In aerated conditions, adding $5 \mathrm{mM}$ clear metavanadate reduced the cathodic current by almost 4 orders of magnitude considering extrapolation of the cur rent to $-700 \mathrm{mV} \mathrm{SCE}$. Interestingly, in deaerated conditions, the measured current was larger than in aerated conditions when $5 \mathrm{mM}$ metavanadate was added. Moreover, the current was larger than the current measured in deaerated conditions with no inhibitor from $-950 \mathrm{mV} \mathrm{SCE}$ to about $-1250 \mathrm{mV}$ SCE. A similar trend is shown in Fig. $11 \mathrm{~b}$ for a $\mathrm{Cu}$ electrode. In this case, however, the cathodic current measured in aerated $0.5 \mathrm{M} \mathrm{NaCl}$ with $5 \mathrm{mM}$ clear metavanadate was larger than the current measured in the same electrolyte under deaerated conditions.

The analysis of these polarization curves is complex. For the AA2024-T3 case, the presence of monovanadates in aerated $0.5 \mathrm{M} \mathrm{NaCl}$ possibly completely blocked the local cathodes by adsorbing on IMCs. All species present in the electrolyte $\left(\mathrm{Na}^{+}, \mathrm{Cl}^{-}, \mathrm{O}_{2}, \mathrm{~V}_{1}, \mathrm{~V}_{2}, \mathrm{~V}_{4}\right.$

Fig. 11. Cathodic polarization curves of AA2024-T3 in aerated and de-aerated $0.5 \mathrm{M} \mathrm{NaCl}$ with $5 \mathrm{mM}$ clear metavanadate containing $2.6 \mathrm{mM} \mathrm{V}_{1}$ for (a) AA2024-T3 and (b) pure $\mathrm{Cu}$.
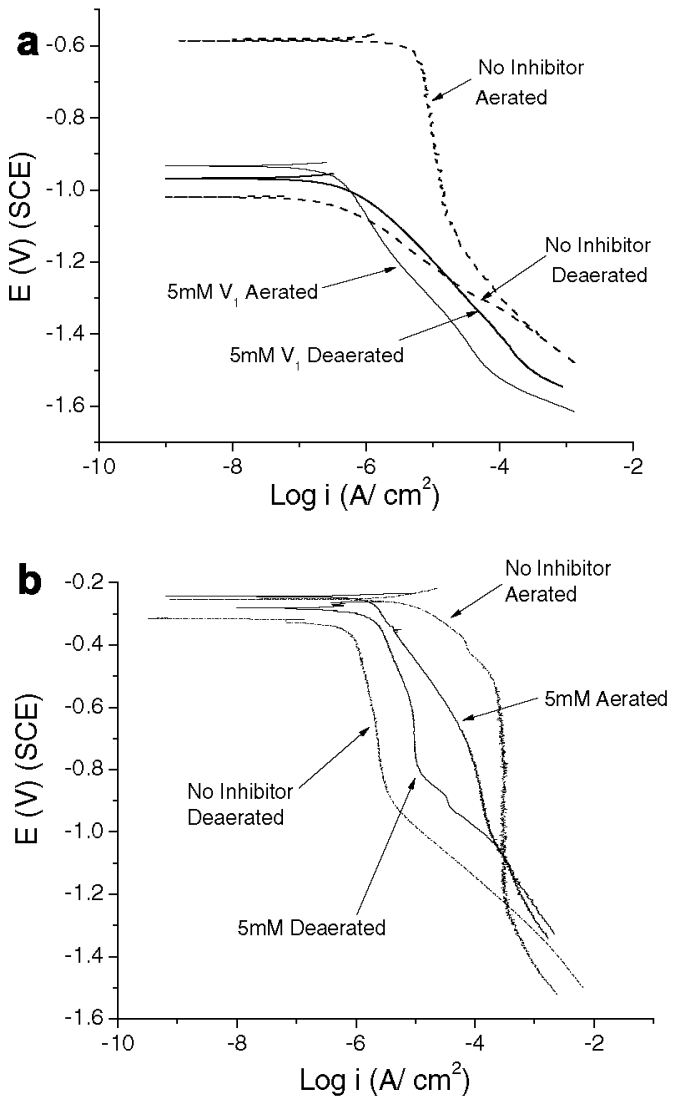
and $\mathrm{V}_{5}$ ) compete for absorption sites. Taking into account the evidence presented here, it is hypothesized that the rapid adsorption of monovanadates displaces other species, forming an adsorbed film at the surface. The consequence of the surface coverage is slower kinetics of the ORR as shown by the extremely large reduction in cathodic current.

Reduction of oxygen is a rather complex phenomenon [42,43]. It can occur by 2- or 4electron pathways with the formation of numerous intermediates such as superoxide $\left(\mathrm{O}_{2}{ }^{-}\right)$, peroxide $\left(\mathrm{H}_{2} \mathrm{O}_{2}, \mathrm{HO}_{2}{ }^{-}\right)$, and hydroxyl radical $\left(\mathrm{OH}^{-}\right)$[42-44]. As shown by several researchers, oxygen reduction is strongly affected by adsorption [42-44]. Adsorption of $\mathrm{O}_{2}$ to metal surfaces weakens the $\mathrm{O}-\mathrm{O}$ bonds and/or its reduction products accelerating the kinetics of the ORR [42]. In this context, prevention of $\mathrm{O}_{2}$ adsorption is an effective means of corrosion control in aerated environments $[28,29,45-47]$. As an example, on modified carbon electrode surfaces the ORR is forced to occur by superoxide if adsorption of $\mathrm{O}_{2}$ is completely suppressed [42,43]. If the ORR occurs via $\mathrm{O}_{2}^{-}$formation, oxygen becomes a weak oxidizing agent, since the effective potential decreases from $1.23 \mathrm{~V}$ SHE to $-0.3 \mathrm{~V}$ SHE [42,43]. Thus, adsorption of monovanadates on AA2024-T3 surfaces may limit $\mathrm{O}_{2}$ adsorption and the subsequent rupture of the $\mathrm{O}-\mathrm{O}$ bonds. Another possibility is that the presence of a monovanadate surface film impedes electron transfer, making $\mathrm{O}_{2}$ reduction more difficult. In addition, according to Fig. 11, evolution of $\mathrm{H}_{2}$ gas was observed at much lower potentials (about -1.5 V SCE).

In deaerated $0.5 \mathrm{M} \mathrm{NaCl}$ with metavanadates, the cathodic current was larger than in the aerated case. The larger cathodic current is related to the electrochemical reduction of monovanadate. The evolution of $\mathrm{H}_{2}(\mathrm{~g})$ was also shifted toward lower potentials in the deaerated case. Comparing aerated and deaerated cathodic polarization curves, it can be hypothesized that the reduction of monovanadates is somehow limited by the presence of oxygen in the solution, resulting in the lower cathodic current. Likewise, since both polarization curves have the same slope, suggesting a similar reduction reaction, it seems possible that the reduction of monovanadates occurred even in aerated conditions but at a lower rate due to a synergistic effect with $\mathrm{O}_{2}$, which may keep part of the adsorbed mono vanadates in the $5+$ oxidation state by rapidly re-oxidizing any reduced molecule.

A similar interpretation can be given to the cathodic polarization curves shown in Fig. 11b. Whereas local reduction of oxygen on AA2024-T3 is limited only to IMCs, $\mathrm{Cu}$ surfaces have a much larger cathodic area. In such a case, adsorption of monovanadates does not entirely cover the active surface sites. Therefore, oxygen can still be adsorbed and reduced on the sites not blocked by the inhibitor. The result is a cathodic polarization plot that represents a convolution of both oxygen and monovanadate reduction. Consequently, the cathodic current was lower than the current measured in aerated $0.5 \mathrm{M} \mathrm{NaCl}$ with no inhibitor but larger than the current measured in deaerated $0.5 \mathrm{M} \mathrm{NaCl}$ with metavanadates. The mixed $\mathrm{O}_{2}$ and monovanadate reduction complicates the interpretation of the data. However, it is clear that in deaerated conditions, the measured cathodic current includes the reduction of monovanadates. On the other hand, it is not clear why the cathodic polarization curves in deaerated $0.5 \mathrm{M} \mathrm{NaCl}$ with metavanadates showed an apparent diffusion control region. The diffusion of monovanadates from the bulk to the active sites not blocked by the inhibitor is likely to be the rate limiting step. The problem of this interpretation is the calculated diffusion coefficient $(D)$ for monovanadate. Assuming a diffusion layer thickness, $\delta$, of $10^{-3} \mathrm{~cm}$ [48], a measured limiting current density $i_{\mathrm{L}}$ of $9 \times 10^{-6} \mathrm{~A} / \mathrm{cm}^{2}$, a concentration gradient of $\mathrm{V} 1$ of $1.6 \mathrm{mM}$, and considering that the number of electrons involve in the reduction is 1 , a diffusion coefficient of approximately $1 \times 10^{-8} \mathrm{~cm}^{2} / \mathrm{s}$ is 
obtained. This value for $D$ is extremely low for diffusion in liquid phase and may suggest that the process is not under diffusion control even though an apparent limiting current was observed [49].

In aerated and deaerated conditions at an applied potential of $-600 \mathrm{mV} \mathrm{SCE}$, injection of orange decavanadate solutions gave a current spike, Figs. 2 and 5. The duration of the transient event varied between experiments. For aerated conditions, only $27 \%$ reduction in the cathodic current was observed at the end of the experiment. Current spikes were also observed on AA2024-T3 samples, which lasted approximately 7-8 min. In deaerated conditions, the current reached a steady state value of about $-50 \mu \mathrm{A} / \mathrm{cm}^{2}$, which is $500 \mathrm{x}$ higher than the current prior to injection. In both aerated and deaerated solutions, the cur rent peak must be associated with the electrochemical reduction of decavanadates. According to Fig. 5, the reduction of decavanadate is not self-limiting. Compared with the reduction of metavanadates, the steady state current reached after injection of decavanadates was much larger. This indicates that the reduction of decavanadates is kinetically favoured over the reduction of monovanadates.

The integration of the current peaks for both aerated and deaerated conditions is shown in Fig. 12. Reduction from $\mathrm{V}^{5+}$ to $\mathrm{V}^{4+}$, and an average size of $750 \mathrm{pm}$ for the decavanadate

Fig. 12. Concentration of the reduced species and number of monolayers as a function of immersion time for $\mathrm{Cu}$ after
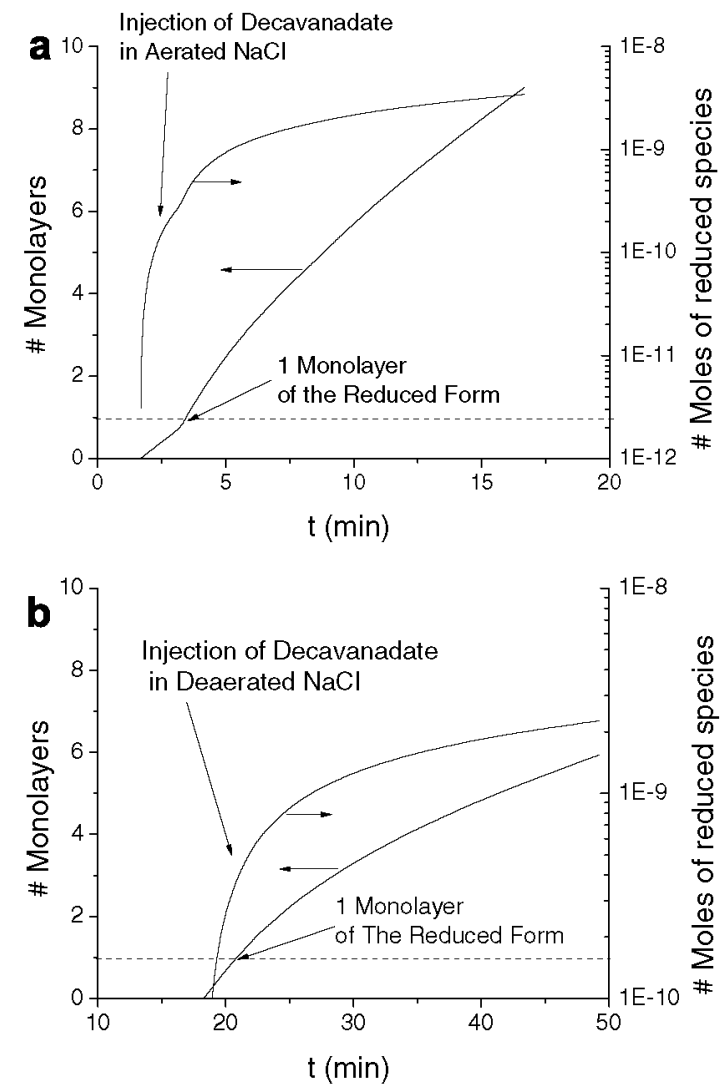

injection of orange solution in (a) aerated and (b) deaerated $0.5 \mathrm{M} \mathrm{NaCl}$. 
molecule were assumed for the integration [26,27]. In good agreement with other results $[18,26,27]$, integration of the current peaks in both aerated and deaerated electrolytes suggested the formation of 10 monolayers. Since this calculation does not account for the possible dissolution of the film, 10 monolayers represent the maximum number of monolayers formed. Nevertheless, the formation of several monolayers suggests the development of a poorly protective film of a reduced vanadate species.

Cathodic polarization curves of AA2024-T3 and pure $\mathrm{Cu}$ in aerated and deaerated conditions with and without decavanadates are shown in Fig. 13. In aerated conditions, addition of $5 \mathrm{mM}$ orange decavanadate (approximately $0.45 \mathrm{mM} \mathrm{V}_{10}$ ) moderately reduced the kinetics of the ORR on AA2024-T3. The OCP was approximately $-800 \mathrm{mV}$ SCE. A limiting current of about $-10 \mu \mathrm{A} / \mathrm{cm}$ was observed. Likewise, the evolution of hydrogen gas was shifted towards more negative potentials. In deaerated conditions, the OCP was slightly more negative, reaching $-870 \mathrm{mV} \mathrm{SCE}$. The cathodic current in deaerated conditions was lower than in aerated conditions but higher than the current obtained in deaerated $0.5 \mathrm{M} \mathrm{NaCl}$ with no inhibitor. Comparing aerated and deaerated cathodic polarization curves, it can be seen that the cathodic current measured in aerated conditions is composed of the reduction of both oxygen and decavanadate. This indicates that
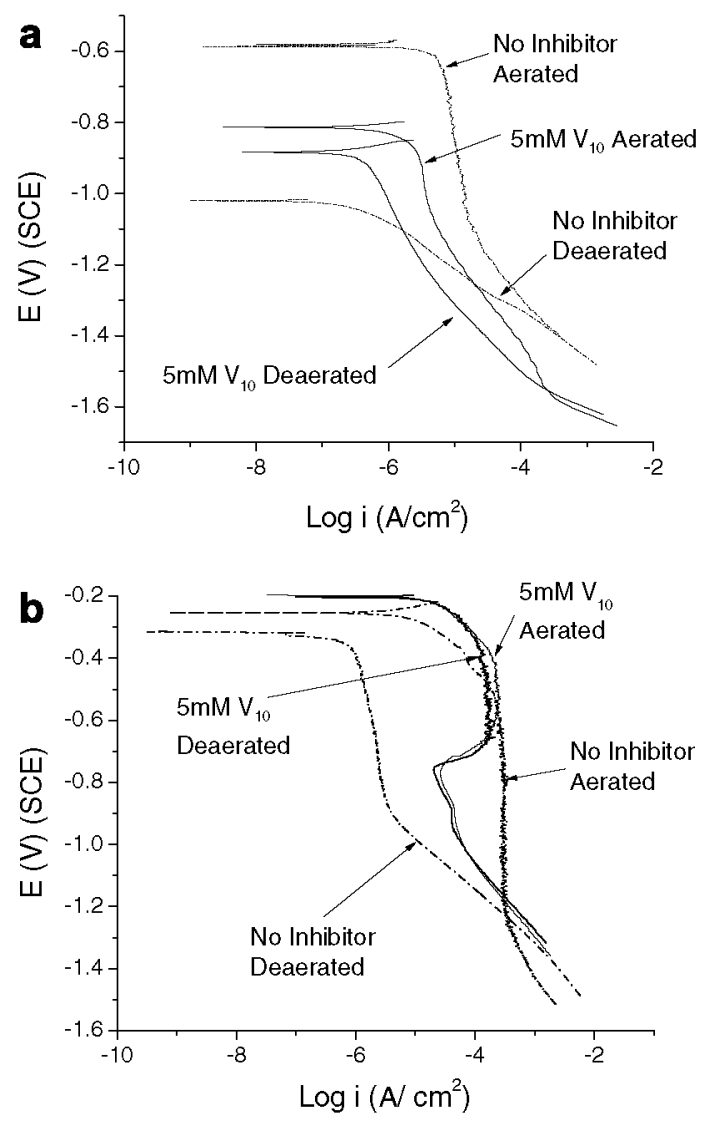

Fig. 13. Cathodic polarization curves in aerated and de-aerated $0.5 \mathrm{M} \mathrm{NaCl}$ with, $5 \mathrm{mM}$ orange decavanadate containing approximately $0.4 \mathrm{mM} \mathrm{V} \mathrm{V}_{10}$ for (a) AA2023-T3 and (b) pure $\mathrm{Cu}$. 
when decavanadates are present and monovanadates are absent, adsorption on the local cathodic sites is not complete, allowing oxygen to reduce on the unprotected IMCs. The partial coverage of local cathodes and the easier reduction of decavanadates result in the lower inhibition efficiency reported previously [18]. These findings could also explain why the inhibition efficiency of solutions containing decavanadates decreased with incremental concentrations of $\mathrm{V}_{10}[18,26]$. As the concentration increases, the amount of reduction of decavanadates is expected to increase accordingly, giving as result a larger cathodic current during polarization experiments. This larger cathodic current resulted in the poorer inhibition efficiency.

The effects of decavanadates are more dramatic on $\mathrm{Cu}$ surfaces (Fig. 13b). Cathodic polarization curves in aerated and deaerated solutions containing $5 \mathrm{mM}$ vanadate looked almost identical. Therefore, the limiting current could be related to diffusion controlled reduction of decavanadates rather than oxygen. The calculated diffusion coefficient for decavanadates in such conditions is approximately $3 \times 10^{-8} \mathrm{~cm}^{2} / \mathrm{s}$. Similar to the case of reduction of monovanadates; this diffusivity is extremely low for diffusion in liquid phase. This may also suggest that even though an apparent diffusion limited region was observed, the process was not under diffusion control. A similar anomalous behaviour was reported by Scully and coworkers for molybdates on $\mathrm{Cu}$ electrodes [50]. The decay in current that occurred at approximately $-650 \mathrm{mV} \mathrm{SCE}$, could be related with the formation of a surface film that reduced charge transference. As in the case of molybdates [26], the subsequent increase in current is possibly the result of the electrochemical reduction of the surface film.

These results are of interest due to the fact that pure $\mathrm{Cu}$ represents the upper limit of Sphase de-alloying and $\mathrm{Cu}$ redistribution on AA2024-T3 surfaces [3,51-53]. Thus, as AA2024T3 corrodes in electrolytes containing $\mathrm{Cl}^{-}$and decavanadates, $\mathrm{Cu}$ redistribution will significantly increase the ability of the surface to sustain not only $\mathrm{O}_{2}$ reduction but also reduction of decavanadates. The consequence of the faster reduction kinetics is an accelerated attack, which eventually will increase the extent of $\mathrm{Cu}$ re-deposition, increasing the kinetics of V10 reduction even further.

\subsection{XPS and residual protection}

The spectra obtained after exposure at fixed cathodic potentials to solutions containing either monovanadates or decavanadates showed the presence of vanadium peaks (Fig. 6). The binding energy in all the experiments was approximately $516.3 \mathrm{eV}$. According to the literature, this binding energy corresponds to a 4+ oxidation state [54]. However, proper interpretation of the data is rather complex. All the oxidation states lie in a very narrow range of $2 \mathrm{eV} \mathrm{[55].} \mathrm{The}$ binding energy increases with incremental oxidation state [55]. In addition, binding energies are generally reported for bulk oxides. Due to interactions with metallic surfaces, the binding energy adsorbed vanadates may vary from the binding energies reported for the oxides [54-57]. An attempt to obtain a calibration curve using bulk oxides with oxidation states varying from $5+$ to $2+$ was made. For the lower oxidation states $(2+$ to $4+)$ the binding energies were in good agreement with the literature [54-57]. However, the binding energy of $\mathrm{V}_{2} \mathrm{O}_{5}$ (5+ oxidation state) gave values close to a 4+ oxidation state (approximately $516.16 \mathrm{eV}$ ). Sputter etching of the oxide with ionized Ar did not produce any change in binding energy. After removal from the XPS chamber, the initially orange oxide appeared black, which is the colour of the oxides of lower 
oxidation state. The exact explanation for this phenomenon is not clear but it suggests that photoreduction during XPS analysis may occur. Therefore, it was impossible to determine from the XPS data if the V-rich film formed during exposure at a fixed cathodic potential is in the $4+$ or $5+$ oxidation state.

Re-exposure of samples pre-treated with the different inhibitors showed that the surface film did not impart residual protection. The current density during exposure to aerated $0.5 \mathrm{M} \mathrm{NaCl}$ at nearly neutral $\mathrm{pH}$ with no inhibitor was identical to the current density measured for untreated samples.

\subsection{Mechanisms of Inhibition}

Monovanadates were proven to be outstanding inhibitors of the ORR [18]. According to the evidence presented here, monovanadates seem to impart the outstanding corrosion protection by rapid adsorption, which follows a Langmuir isotherm with [V1]. Coverage of the local cathodes displaces $\mathrm{O}_{2}$ and probably $\mathrm{Cl}^{-}$from the AA2024-T3 surface. Even if oxygen can be adsorbed on top of the monovanadate film, the transfer of electrons through the ad layer may be discouraged. Reduction of monovanadates can occur after adsorption, but the kinetics are relatively slow. In aerated electrolytes, the rate of monovanadate reduction is slower than in deaerated conditions. The reduction of the inhibitor is not self-limiting, suggesting that the corrosion protection is imparted by the adsorbed monovanadates rather than by the formation of a protective film from their reduced form. Likewise, the fact that incremental injections of metavanadates to the cathode of different split cells did not further reduce the galvanic current $[26,27]$ is in good agreement with the proposed adsorption mechanisms. If most of the cathodes were blocked during the first injection of inhibitor, no significant effects would be expected by increasing the concentration. In addition to the potent reduction of the ORR, protection of $\mathrm{Al}_{2} \mathrm{CuMg}$ selective dissolution was reported in [26]. Anodic polarization curves of AA2024-T3 in deaerated $0.5 \mathrm{M} \mathrm{NaCl}$ with and with out $5 \mathrm{mM}$ metavanadate are shown in Fig. 14 to illustrate these findings. Protection of S-phase transient dissolution increases the corrosion resistance of AA2024-T3 during OCP exposure. The mechanism of protection of this transient dissolution is not clear. However,

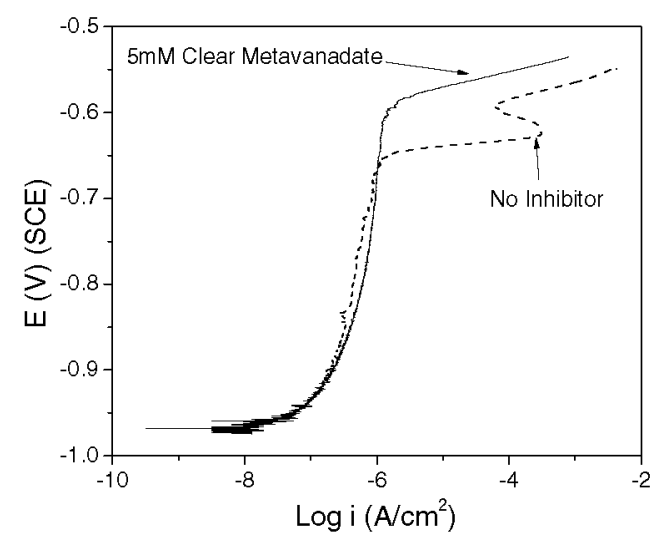

Fig. 14. Anodic polarization curves of AA2024-T3 in deaerated $0.5 \mathrm{M} \mathrm{NaCl}$ with and without $5 \mathrm{mM}$ clear metavanadate. 
it is possible that adsorption of monovanadates on the $\mathrm{Al}$ matrix displaces adsorbed $\mathrm{Cl}^{-}$. Although the mechanisms of pit initiation are still an issue of debate, it is generally agreed that $\mathrm{Cl}^{-}$either thins the passive film or diffuses through it [58]. Therefore, as indicated by several researchers [59-62], a critical step for pit initiation is adsorption of $\mathrm{Cl}$ at the surface. If monovanadates displace $\mathrm{Cl}^{-}$from the local anodes, the mechanisms of breakdown of the passive film are discouraged. Thus, in polarization curves, a displacement of $\mathrm{Cl}^{-}$from the surface by adsorption of monovanadates would be reflected by an increase the breakdown potential of S-phase particles.

In contrast to metavanadates, decavanadate was proven to be a poor corrosion inhibitor. Reduction of decavanadates took place in both aerated and deaerated conditions. Decavanadates were readily reduced upon injection. Adsorption on local cathodes is not complete and the ORR can still occur at a fast rate. In addition, reduction of decavanadate on $\mathrm{Cu}$ seems to be favoured. Thus, as AA2024-T3 suffers selective dissolution of S-phase particles, with the subsequent redistribution of $\mathrm{Cu}$ at the surface, the rate of reduction of decavanadates will increase accordingly. These findings suggest that formation of decavanadates should be avoided to obtain the best inhibition performance. As shown previously [18], formation of decavanadates from clear metavanadate solutions takes place by local acidification below a critical $\mathrm{pH}$ of about 3-4. Consequently, it is desirable to maintain the $\mathrm{pH}$ of the electrolyte above the critical $\mathrm{pH}$ at any time. This should not be an issue during atmospheric exposure of aircraft since the local electrolyte is thought to remain neutral or slightly basic [49].

\section{Conclusions}

The mechanisms of inhibition by clear solutions containing monovanadates and orange solutions containing decavanadates but no monovanadates were investigated by chronoamperometry and polarization curves. The following conclusions can be obtained:

1. Injection of clear metavanadate solutions to aerated $0.5 \mathrm{M} \mathrm{NaCl}$ at varied applied potentials showed a large reduction in cathodic current. The extent of inhibition was a function of the applied potential. No current spike was observed even at large cathodic overpotentials. The extent of reduction in the rate of ORR was similar to that of chromate.

2. Construction of adsorption isotherms showed that monovanadates are adsorbed on the surface following a Langmuir isotherm. The critical concentration of monovanadate was $0.05 \mathrm{mM}$, similar to the reported critical concentration of $\mathrm{Cr}^{6+}$.

3. Corrosion inhibition of AA2024-T3 by monovanadates might occur by the formation of an adsorbed layer. Reduction of clear metavanadate solution was very slow, and it took approximately $35 \mathrm{~min}$ to develop a monolayer of the reduced form. The adsorption of the inhibitor blocked reactive sites on IMCs, discouraging the ORR. Adsorption of the inhibitor on the $\mathrm{Al}$ matrix might also displace $\mathrm{Cl}^{-}$adsorption, increasing the stability of the passive film and reducing the breakdown of S-phase particles.

4. Compared with metavanadate solutions, decavanadates are not good inhibitors of the ORR. Decavanadates showed a sharp current spike after injection on both $\mathrm{Cu}$ and AA2024-T3 at varied applied cathodic potentials.

5. XPS experiments could not conclusively determine the V oxidation state on the AA2024 surface owing to the possibility of photoreduction during measurement. 


\section{References}

[1] J.R. Davis, ASM Specialty Handbook: Aluminum and Aluminum Alloys, ASM International, 1993 (Chapter 2) pp. 31-35.

[2] C. Kammer, Aluminum Handbook, first ed., vol. 1, Aluminum-Verlag, 1999 (Chapter 4) pp. 125-143.

[3] N. Birbilis, R.G. Buchheit, J. Electrochem. Soc. 152 (2005) B140-B151.

[4] C. Blanc, B. Lavelle, G. Mankowski, Corr. Sci. 39 (1997) 495-510.

[5] R.G. Buchheit, J. Electrochem. Soc. 142 (1995) 3994-3996.

[6] G.S. Chen, M. Gao, R.P. Wei, Corrosion 52 (1996) 8-15.

[7] W. Zhang, G.S. Frankel, Electrochem. Solid-State Lett. 3 (2000) 268-272.

[8] W. Zhang, G.S. Frankel, J. Electrochem. Soc. 149 (2002) B510-B519.

[9] W. Zhang, G.S. Frankel, Electrochim. Acta 48 (2003) 1193. [10] R.G. Buchheit, R.G.

Buchheit, ECS PV2002-13, Pennington, NJ, 2002, p. 430.

[11] P. Campestrini, H. Terryn, J. Vereecken, J.H.W.D. Wit, J. Electrochem. Soc. 151 (2004) B370-B377. [12] G.S. Frankel, R.L. McCreery, Electrochem. Soc. Interface (2001) 34-38. [13] P.L. Hagans, C.M. Haas, ASM Handbook, Surface Engineering, 10th ed., vol. 5, ASM International, Metals

Park, OH, 1994. [14] M. Kendig, R.G. Buchheit, Corrosion 59 (2003)

379-400. [15] M. Kendig, C. Yan, J. Electrochem. Soc. 151 (2004) B679-

B682.

[16] M. Koudelkova, J. Augustynski, H. Berthou, J. Electrochem. Soc. 124 (1977) 1165-1168. [17] P.G. Sheasby, R.

Pinner, The Surface Treatment and Finishing of Aluminum and its Alloys, vol. 1, ASM

International, Materials Park, OH, 2001 (Chapter 5) pp. 231-245. [18] M. Iannuzzi, T. Young, G.S.

Frankel, J. Electrochem. Soc. 153 (2006) B533. [19] A. Gorzsas, K. Getty, I. Andersson, L. Petersson, Royal

Soc. Chem., Dalton Trans. (2004) 2873. [20] E. Heath, O.W. Howarth, J. Chem. Soc., Dalton Trans. (1981)

1105-1110. [21] A.S. Tracey, Coord. Chem. Rev. 237 (2003) 113-121.

[22] A.S. Tracey, J.S. Jaswal, S.J. Angus-Dunne, Inorg. Chem. 34 (1995) 5680-5685. [23] A.S. Tracey, C.H. Leon-

Lai, Inorg. Chem. 30 (1991) 3200-3209. [24] M. Aureliano, R.M.C. Gandara, J. Inorg. Biochem. 99 (2005) 979-985.

[25] J.W. Larson, J. Chem. Eng. Data 40 (1995) 1276-1280. [26] M. Iannuzzi, Inhibition of Al Alloy 2024-T3

Corrosion by Vanadates, PhD Dissertation, The Ohio State

University, 2006. [27] M. Iannuzzi, G.S. Frankel, Electrochim. Acta, in press.

[28] W.J. Clark, R.L. McCreer, J. Electrochem. Soc. 149 (2002) B379-B386.

[29] W.J. Clark, J.D. Ramsey, R.L. McCreery, G.S. Frankel, J. Electrochem. Soc. 149 (5) (2002) B179-B185. [30]

V.S. Sastri, Corrosion Inhibitors, Principle and Applications, John Wiley \& Son, West Sussex, England, 1998, p. 33. [31] P. Kern, D. Landolt, J. Electrochem. Soc. 148 (2001) B228-B235. [32] I. Langmuir, J. Am.

Chem. Soc. 40 (1918) 1361-1369. [33] M. Kaminski, Z. Szklarska-Smialowska, Corr. Sci. 13 (1973) 553-555. [34] R. Gasparac, C.R. Martin, E. Stunpnisek-Lisac, J. Electrochem. Soc. 147 (2000) 991-998. [35] R.G. Nuzzo, R.R.

Zegarsky, L.H. Dubois, J. Am. Chem. Soc. 109 (1987) 733-740. [36] M. Pourbaix, Atlas of Electrochemical Equilibria, second ed., NACE, Houston, Texas, 1974, pp. 237. [37] V. Guillaumin, P. Schmutz, G.S. Frankel, J. Electrochem. Soc. 148 (2001) B163-B173. [38] M. Kendig, S. Jeanjaquet, R. Addison, J. Waldrop, Surf. Coat Technol. 140 (2001) 58-66. [39] P. Schmutz, G.S. Frankel, J. Electrochem. Soc. 145 (1998) 2285-2295. [40] W.W. Damaskin, O.A. Pietrij, W.W. Batrakow, Adsorption of Organic Compounds on Electrodes, Plenum Press, New York, 1971. [41] A.F. Holleman, E. Wiberg, Inorganic Chemistry, Academic Press, Berlin/New York, 2001. [42] H.H. Yang, R.L. McCreer, J. Electrochem. Soc. 147 (1996) 3420-3428. [43] J. Xu, W. Huang, R.L. McCreer, J. Electroanal. Chem. 410 (1996) 235-242. [44] S. Strbac, R.R. Adzic, Electrochim. Acta 41 (1996) 2903-2908. [45] B.L. Hurley, R.L. McCreery, J. Electrochem. Soc. 150 (2003) B367.

[46] L. Xia, E. Akiyama, G.S. Frankel, R.L. McCreery, J. Electrochem. Soc. 147 (2000) 2556-2562. [47] J. Zhao, L. Xia, A. Sehgal, D. Lu, R.L. McCreery, G.S. Frankel, Surf. Coat Technol. 140 (2001) 51-57. [48] K.J. Vetter, Electrochemical Kinetics, Academic Press, New York, 1967. 
[49] G.O. Ilevbare, J.R. Scully, Corrosion 57 (2001) 134-152.

[50] F.J. Presuel-Moreno, M.A. Jakab, J.R. Scully, J. Electrochem. Soc. 152 (2005) B376-B387.

[51] R.G. Buchheit, R.P. Grant, P.F. Hlava, B. McKenzie, G.L. Zender, J. Electrochem. Soc. 144 (1997) 2621-

2628. [52] M.B. Vukmirovic, N. Dimitrov, K. Sieradzki, J. Electrochem. Soc. 149 (2002) B428-B439. [53] M.B.

Vukmirovic, N. Vasiljevic, N. Dimitrov, K. Sieradzki, J. Electrochem. Soc. 150 (2003) B10-B15. [54] J.

Kasperkiewicz, J.A. Kovacich, D. Lichtman, J. Electron. Spectrosc. Relat. Phenom. 32 (1983) 123-132. [55]

Handbook of X-Ray Photoelectron Spectroscopy, Perkin-Elmer Co., 1992. [56] R.J. Colton, A.M. Guzman, J.W.

Robalais, J. Appl. Phys. 49 (1978) 409.

[57] N.I. Nefedov, Y.V. Salyn, G. Leonhardt, J. Electron. Spectrosc. Relat. Phenom. 10 (1977) 121-124. [58] J.R. Galvele, S.M. Demicheli, Corr. Sci. 10 (1970) 795-807. [59] E. Ghali, Uhlig's Corrosion Handbook, second ed., CANMET Materials Laboratory, Ottawa, Ontario,

Canada, 1998. [60] E. McCafferty, Corr. Sci. 37 (1995) 481-492. [61] E. McCafferty, Corr. Sci. 45 (2003)

1421-1438. [62] F.D. Wall, C.M. Johnson, J.C. Barbour, M.A. Martinez, J. Electrochem. Soc. 151 (2004) B77-

B81. 